\title{
Effects of intraoperative PEEP optimization on postoperative pulmonary complications and the inflammatory response: study protocol for a randomized controlled trial
}

Zoltán Ruszkai ${ }^{1}$, Erika Kiss², Ildikó László ${ }^{2}$ Fanni Gyura', Erika Surány' ${ }^{1}$ Péter Töhötöm Bartha', Gergely Péter Bokrétás ${ }^{1}$, Edit Rácz ${ }^{1}$ István Buzogány³ ${ }^{3}$ Zoltán Bajory ${ }^{4}$, Erzsébet Hajdú ${ }^{4}$ and Zsolt Molnár $2^{*}$

\begin{abstract}
Background: Patients undergoing general anesthesia and mechanical ventilation during major abdominal surgery commonly develop pulmonary atelectasis and/or hyperdistention of the lungs. Recent studies show benefits of lung-protective mechanical ventilation with the use of low tidal volumes, a moderate level of positive end-expiratory pressure (PEEP) and regular alveolar recruitment maneuvers during general anesthesia, even in patients with healthy lungs. The purpose of this clinical trial is to evaluate the effects of intraoperative lung-protective mechanical ventilation, using individualized PEEP values, on postoperative pulmonary complications and the inflammatory response.
\end{abstract}

Methods/design: A total number of 40 patients with bladder cancer undergoing open radical cystectomy and urinary diversion (ileal conduit or orthotopic bladder substitute) will be enrolled and randomized into a study (SG) and a control group (CG). Standard lung-protective ventilation with a PEEP of $6 \mathrm{cmH}_{2} \mathrm{O}$ will be applied in the CG and an optimal PEEP value determined during a static pulmonary compliance (Cstat)-directed PEEP titration procedure will be used in the SG. Low tidal volumes ( $6 \mathrm{~mL} / \mathrm{Kg}$ ideal bodyweight) and a fraction of inspired oxygen of 0.5 will be applied in both groups. After surgery both groups will receive standard postoperative management. Primary endpoints are postoperative pulmonary complications and serum procalcitonin kinetics during and after surgery until the third postoperative day. Secondary and tertiary endpoints will be: organ dysfunction as monitored by the Sequential Organ Failure Assessment Score, in-hospital stay, 28-day and in-hospital mortality.

Discussion: This trial will assess the possible benefits or disadvantages of an individualized lung-protective mechanical ventilation strategy during open radical cystectomy and urinary diversion regarding postoperative pulmonary complications and the inflammatory response.

Trial registration: ClinicalTrials.gov, ID: NCT02931409. Registered on 5 October 2016.

Keywords: Positive end-expiratory pressure, Static pulmonary compliance, Lung-protective ventilation, Radical cystectomy, Postoperative pulmonary complications, Procalcitonin

\footnotetext{
* Correspondence: molnar.lajos.zsolt@med.u-szeged.hu

${ }^{2}$ Department of Anaesthesiology and Intensive Therapy, University of Szeged,

Semmelweis u. 6, Szeged 6725, Hungary

Full list of author information is available at the end of the article
} 


\section{Background}

Patients undergoing general anesthesia and mechanical ventilation during major abdominal surgery commonly develop pulmonary atelectasis and/or hyperinflation of the lungs leading to complications either intraoperatively or in the postoperative period, resulting in ventilatorinduced lung injury (VILI) $[1,2]$.

Lung-protective mechanical ventilation (LPV), by applying "low" tidal volumes (TV $=6 \mathrm{~mL} / \mathrm{Kg}$ of ideal bodyweight, IBW), optimal positive end-expiratory pressure (PEEP) and regular alveolar recruitment maneuvers (ARM) in case of acute respiratory distress syndrome (ARDS) have been shown to be advantageous in critically ill patients. Recent studies have also shown positive results of LPV and regular ARM during general anesthesia in patients with healthy lungs $[3,4]$. The main advantages of this strategy are improved gas exchange and prevention of either pulmonary atelectasis or VILI [5-7]. However, the effects of applying an optimal level of PEEP have not entirely been evaluated.

There are several types of PEEP titration methods such as dead space fraction (Vds/Vt)-guided or static pulmonary compliance (Cstat)-directed techniques [8-12].

Theoretically, in patients with healthy lungs, during general anesthesia and mechanical ventilation, inadequate PEEP values may lead to decreased pulmonary compliance and gas exchange disorders due to pulmonary atelectasis and/or hyperinflation of the lungs. In our clinical trial, optimal PEEP values will be determined during a static pulmonary compliance-directed PEEP titration procedure to protect from hyperdistention, and regular ARMs will be performed using the sustained airway pressure by the continuous positive airway pressure (CPAP) method, applying $30 \mathrm{cmH}_{2} \mathrm{O}$ of PEEP for $30 \mathrm{~s}$, to prevent atelectasis $[5,13,14]$.

On the one hand major abdominal surgery induces an inflammatory response that is necessary for postoperative recovery (e.g., wound healing), but on the other hand an overwhelming inflammatory response may also lead to adverse events (AEs) such as organ dysfunction [15-19]. Radical cystectomy is considered major surgery; hence, there is an increased risk of postoperative complications. Inappropriate mechanical ventilation during general anesthesia can also lead to an amplified inflammatory response, which theoretically may worsen the postoperative outcome via several mechanisms. However, the relationship between LPV and the postoperative inflammatory response after radical cystectomy has not been investigated yet.

There is strong correlation between the degree of inflammatory response and serum procalcitonin (PCT) concentrations $[20,21]$; hence, there is some rationale in the belief that monitoring the inflammatory response by regular PCT measurements in the postoperative period reflects the host response. Therefore, there is some rationale in monitoring PCT kinetics as an indicator of the host inflammatory response.

The aim of this investigator-initiated, double-center, single-blinded (subject), prospective, randomized controlled trial is to evaluate the effects of intraoperative LPV, applying an individually titrated optimal PEEP, on postoperative pulmonary complications (PPC) and the inflammatory response in patients undergoing radical cystectomy and urinary diversion (ileal conduit or orthotopic bladder substitute). We hypothesized that optimizing intraoperative mechanical ventilation (incorporating LPV, ideal PEEP and ARM) can attenuate the inflammatory response as compared to conventional modes of mechanical ventilation, and hence may result in improved postoperative oxygenation, prevent the occurrence of VILI, and reduce the incidence of organ dysfunction. These anticipated advantages may also improve postoperative recovery and survival rates, shorten in-hospital stay and reduce health care-related costs.

\section{Methods/design \\ Objectives of the study}

The main objectives of this trial are to compare the effects of a standard LPV applying $6 \mathrm{cmH}_{2} \mathrm{O}$ of PEEP to a LPV using an individually titrated optimal PEEP on: (1) oxygenation and PPC, (2) the degree of inflammatory response evaluated by early PCT kinetics $(0,2,6,12,24$, 48 and $72 \mathrm{~h}$ after surgical incision) and (3) to evaluate the relationship between the degree of inflammation and postoperative pulmonary and extrapulmonary complications.

\section{Study endpoints}

The primary outcome variables are PPC and PCT kinetics. PPC are defined as new infiltrates or atelectasis on a chest X-ray, abnormal breathing sounds on auscultation, respiratory failure defined as $\mathrm{PaO}_{2} / \mathrm{FiO}_{2}<300$ or the need for noninvasive or invasive ventilatory support within the first three postoperative days. PCT kinetics will be evaluated during and after surgery. Blood samples will be taken at $0,2,6,12,24,48$ and $72 \mathrm{~h}$ after surgical incision. According to recent data it is expected that PCT values will peak at approximately $24 \mathrm{~h}$ after surgery and that they should decline by approximately $50 \%$ daily in the case of an uneventful postoperative course. Therefore, in addition to the absolute values the change between $\mathrm{T}_{0}-\mathrm{T}_{24}-\mathrm{T}_{48}$ will also be evaluated $[16,22]$.

Secondary outcome variables are extrapulmonary complications: incidence of circulatory failure, gastrointestinal and renal dysfunction, hematologic and coagulation disorders and infection (Table 1).

Tertiary endpoints are intensive care unit (ICU) days, in-hospital stay, in-hospital and 28-day mortality. 
Table 1 Secondary endpoints

\begin{tabular}{|c|c|c|}
\hline Endpoint & Time frame & Detailed description \\
\hline \multirow[t]{10}{*}{ Circulatory failure } & \multirow[t]{10}{*}{28 days } & Hypotension - MAP $<65 \mathrm{mmHg}$ \\
\hline & & $\begin{array}{l}\text { Severe cardiac arrhythmia }-40 / \mathrm{min} \\
<H R>150 / \mathrm{min}\end{array}$ \\
\hline & & $\mathrm{ScvO}_{2}<70 \%$ \\
\hline & & $\mathrm{dCO}_{2}>7 \mathrm{mmHg}$ \\
\hline & & Serum lactate $>2 \mathrm{mmol} / \mathrm{L}$ \\
\hline & & $\begin{array}{l}\text { Severe metabolic acidosis } \\
\text { (actual bicarbonate }<18 \mathrm{mmol} / \mathrm{L} \text { ) }\end{array}$ \\
\hline & & Acute coronary syndrome \\
\hline & & Acute left ventricular failure \\
\hline & & Pulmonary embolism \\
\hline & & Cardiac arrest \\
\hline \multirow{5}{*}{$\begin{array}{l}\text { Gastrointestinal } \\
\text { dysfunction }\end{array}$} & \multirow[t]{5}{*}{28 days } & Constipation \\
\hline & & lleus \\
\hline & & Anastomotic leakage \\
\hline & & Reoperation \\
\hline & & Disorders of liver function \\
\hline Renal dysfunction & 28 days & RIFLE criteria \\
\hline \multirow{2}{*}{$\begin{array}{l}\text { Hematologic and } \\
\text { coagulation disorders }\end{array}$} & \multirow[t]{2}{*}{28 days } & Severe bleeding \\
\hline & & Coagulopathy - INR > 1.5 \\
\hline Infection & 28 days & $\begin{array}{l}\text { Any infection except from } \\
\text { pneumonia }\end{array}$ \\
\hline
\end{tabular}

MAP mean arterial pressure, $\mathrm{HR}$ heart rate, $\mathrm{ScVO}_{2}$ central venous oxygen saturation, $d \mathrm{CO}_{2}$ central venous-to-arterial carbon dioxide gap, INR International Normalized Ratio

\section{Study design}

This is an investigator-initiated, double-center, parallelgroup, single-blinded, interventional, prospective, randomized controlled trial conducted at the Department of Anesthesiology and Intensive Care of Péterfy Sándor Hospital Budapest and at the Department of Anesthesiology and Intensive Therapy of University of Szeged. The first patient will be randomized in October 2016. This protocol conforms to the Consolidated Standards of Reporting Trials (CONSORT) guidelines. Figure 1 shows the Standard Protocol Items: Recommendation for Interventional Trials (SPIRIT) schedule of enrollment, interventions and assessments. The SPIRIT 2013 Checklist is given in Additional file 1.

\section{Blinding, data collection, randomization and record- keeping}

This is a single-blinded (participant) study. Patient data, intraoperative and postoperative measurements, fluid balance, respiratory parameters, laboratory results and clinical status (Sequential Organ Failure Assessment (SOFA) score) will be collected onto Case Report Forms (CRF). CRF and the patient evaluation chart will not be assessed in front of the patient.
Participants will be randomized to the SG or CG in a ratio of 1:1. Randomization will be carried out by a computer-generated blocked randomization list with 10 blocks of four patients per block. Allocation will be stored in sealed, opaque and numbered envelopes. Participants will be included and allocated in numerical order.

All original records (CRF and relevant correspondence) will be archived and secured for 15 years, and then destroyed according to the hospital standards concerning destruction of confidential information.

\section{Selection of the participants}

Patients with bladder cancer scheduled for open radical cystectomy and urinary diversion will be screened and recruited during routine perioperative assessment. Participants fulfilling the inclusion criteria will be asked for their signed informed consent. Withdrawal of consent may be initiated by the participant at any time during the trial.

Inclusion criteria are age over 18 years, patients with bladder cancer undergoing radical cystectomy and urinary diversion (ileal conduit or orthotopic bladder substitute) and provision of signed informed consent.

Exclusion criteria are age below 18 years, American Society of Anesthesiologists (ASA) physical status IV, history of severe chronic obstructive pulmonary disease (COPD, GOLD grades III or IV), history of severe or uncontrolled bronchial asthma, history of severe restrictive pulmonary disease, pulmonary metastases, history of any thoracic surgery, need for thoracic drainage before surgery, renal replacement therapy prior to surgery, congestive heart failure (NYHA grades III or IV), extreme obesity (Body Mass Index, BMI $>35 \mathrm{Kg} / \mathrm{m}^{2}$ ) and lack of patient's consent.

\section{Time course of the study \\ Preoperative assessment and admission}

During standard institutional preoperative assessment, the patient's eligibility for radical cystectomy and urinary diversion will be evaluated. Medical history, laboratory and chest X-ray or computed tomography (CT) scan, 12-lead electrocardiogram (ECG), ASA physical status, BMI, Respiratory Failure Risk Index (RFRI), nutritional risk screening (NRS 2002 tool) and, if required (in case of history of smoking or coronary artery disease), results of spirometry, echocardiography and ergometry will be recorded. Participants fulfilling the inclusion criteria will be asked for their signed informed consent.

After admission to the Department of Urology (on the day before surgery) a central venous catheter will be placed, a blood sample will be taken from included patients for baseline levels of PCT $\left(\mathrm{T}_{0}\right)$, a chest X-ray will be performed and, if there are no exclusion criteria, patients will be randomized into one of the 


\begin{tabular}{|c|c|c|c|c|c|c|c|c|}
\hline \multirow[b]{3}{*}{ TIMEPOINT } & \multicolumn{8}{|c|}{ STUDY PERIOD } \\
\hline & \multicolumn{2}{|c|}{ Enrolment } & \multirow{2}{*}{$\begin{array}{c}\text { Allocation } \\
0 \\
\end{array}$} & \multicolumn{5}{|c|}{ Post-allocation } \\
\hline & $-2 /-1$ week & $-t_{1}$ & & DOS & $\begin{array}{c}P O D \\
1 \\
\end{array}$ & $\begin{array}{c}P O D \\
2 \\
\end{array}$ & $\begin{array}{c}P O D \\
3 \\
\end{array}$ & $\begin{array}{l}P O D \\
4-28 \\
\end{array}$ \\
\hline \multicolumn{9}{|l|}{ ENROLMENT: } \\
\hline $\begin{array}{r}\text { Perioperative } \\
\text { assessment } \\
\text { (pre-screening) }\end{array}$ & $x$ & & & & & & & \\
\hline \multirow{3}{*}{$\begin{array}{r}\text { Eligibility screen } \\
\text { Informed consent } \\
\text { Allocation }\end{array}$} & & $x$ & & & & & & \\
\hline & & $x$ & & & & & & \\
\hline & & & $x$ & & & & & \\
\hline \multicolumn{9}{|l|}{ INTERVENTIONS: } \\
\hline \multirow{2}{*}{$\begin{array}{r}\text { Study Group } \\
\text { Optimal PEEP } \\
\text { Control Group } \\
\text { Standard PEEP } \\
\end{array}$} & & & & $x$ & & & & \\
\hline & & & & $\mathrm{X}$ & & & & \\
\hline \\
\hline \multicolumn{9}{|l|}{$\begin{array}{r}\text { Postoperative } \\
\text { pulmonary } \\
\text { complications }\end{array}$} \\
\hline $\begin{array}{r}\text { Procalcitonin } \\
\text { kinetics }\end{array}$ & & & & 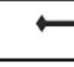 & & & $\rightarrow$ & \\
\hline Adverse events & & & & $x$ & & & & \\
\hline SOFA Score & & & & & $x$ & $x$ & $x$ & \\
\hline $\begin{array}{r}\text { Physical } \\
\text { examinations }\end{array}$ & & & & & $x$ & $x$ & $x$ & $\longmapsto$ \\
\hline \multicolumn{9}{|l|}{ Circulatory failure } \\
\hline \multicolumn{9}{|l|}{$\begin{array}{r}\text { Gastrointestinal } \\
\text { dysfunction }\end{array}$} \\
\hline \multicolumn{9}{|l|}{ Renal dysfunction } \\
\hline $\begin{array}{r}\text { Hematologic and } \\
\text { Coagulation } \\
\text { disorders }\end{array}$ & & & & & & & & \\
\hline Infection & & & & & $\hookleftarrow$ & & & $\longrightarrow$ \\
\hline ICU-days & & & & $x$ & $x$ & $x$ & $x$ & $\longmapsto$ \\
\hline In-hospital stay & & & & & & & & $\longmapsto$ \\
\hline $\begin{array}{r}\text { In-hospital } \\
\text { mortality }\end{array}$ & & & & & & & & $\longrightarrow$ \\
\hline 28-days mortality & & & & $\leftarrow$ & & & & 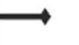 \\
\hline
\end{tabular}

Fig. 1 Standard Protocol Items: Recommendation for Interventional Trials (SPIRIT) schedule of enrollment, interventions and assessments. DOS day of surgery, POD postoperative day, SOFA Sequential Organ Failure Assessment, ICU intensive care unit

study groups. Patients will be given oral carbohydrate loading (maltodextrin) 12, 8 and $2 \mathrm{~h}$ before surgery, $1000 \mathrm{~mL}$ of crystalloid solution will be given and antimicrobial prophylaxis will be introduced using ciprofloxacin and metronidazole $30 \mathrm{~min}$ before surgical incision. Antimicrobial prophylaxis will be continued for $72 \mathrm{~h}(2 \times 400 \mathrm{mg}$ ciprofloxacin and $3 \times$ $500 \mathrm{mg}$ metronidazole per day). Deep vein thrombosis prophylaxis will be carried out using low-molecularweight heparin (LMWH).

\section{Intraoperative care}

Before induction of anesthesia an epidural catheter and an arterial cannula will be inserted for invasive arterial blood pressure monitoring and blood gas sampling.

Immediately after induction of anesthesia and orotracheal intubation, once a steady state has been reached (Table 2), all patients will be submitted to an ARM using the sustained airway pressure by the CPAP method, applying $30 \mathrm{cmH}_{2} \mathrm{O}$ PEEP for $30 \mathrm{~s}$. After ARM, PEEP will be set to $6 \mathrm{cmH}_{2} \mathrm{O}$ in the CG ("standard PEEP") and 
Table 2 Steady state after induction of anesthesia

\begin{tabular}{lll}
\hline & Parameter & Value \\
\hline Hemodynamics & Mean arterial pressure & $65 \mathrm{mmHg}<\mathrm{MAP}<90 \mathrm{mmHg}$ \\
& Heart rate & $50 / \mathrm{min}<\mathrm{HR}<100 / \mathrm{min}$ \\
Ventilation & $\mathrm{SpO}_{2}$ & $\geq 96 \%$ \\
& $\mathrm{EtCO}_{2}$ & $35-40 \mathrm{mmHg}$ \\
Anesthetics & EtSevo & $1.0 \mathrm{MAC}$ \\
\hline
\end{tabular}

$M A P$ mean arterial pressure, $H R$ heart rate, $\mathrm{SpO}_{2}$ peripheral capillary oxygen saturation, $\mathrm{EtCO}_{2}$ end-tidal carbon dioxide partial pressure, EtSevo end-tidal sevoflurane concentration, MAC minimal alveolar concentration

LPV $\left(\mathrm{TV}=6 \mathrm{~mL} / \mathrm{Kg} \mathrm{IBW}, \mathrm{FiO}_{2}=0.5\right)$ will be performed. In the SG ("optimal PEEP") PEEP will be determined during a Cstat-directed decremental PEEP titration procedure. During surgery ARM will be repeated and arterial and central venous blood gas samples (ABGs, CVBGs) will be evaluated every $60 \mathrm{~min}$. In case of decreased oxygen saturation $\left(\mathrm{SpO}_{2}<94 \%\right)$ rescue ARM will be performed using a $\mathrm{FiO}_{2}$ of 1.0. PCT levels will be measured 2, 6, 12, 24, 48 and $72 \mathrm{~h}$ after surgical incision.

Arterial blood pressure, heart rate (HR) and end-tidal carbon dioxide tension $\left(\mathrm{EtCO}_{2}\right)$ will be monitored continuously. Cstat, airway resistance (Raw), Vds/Vt, core temperature and train-of-four relaxometry data will be recorded every $15 \mathrm{~min}$.

During surgery, in cases of hypotension, intravenous norepinephrine will be started to maintain mean arterial pressure above $65 \mathrm{mmHg}$. For intraoperative fluid management patients will receive $3 \mathrm{~mL} / \mathrm{Kg} / \mathrm{h}$ of balanced crystalloid solution until end of surgery. In cases of bleeding, a 200-mL colloid (hydroxyethyl starch, HES) solution bolus and crystalloid substitution will be given. Packed red blood cell (PRBC) transfusion will be given whenever the attending anesthetist feels it necessary.

\section{Postoperative care}

After extubation, patients will be admitted to the ICU. ABGs and CVBGs will be collected and evaluated $(\mathrm{pH}$, base excess (BE), standard bicarbonate $\left(\mathrm{stHCO}^{3-}\right)$, $\left.\mathrm{ScvO}_{2}\right), \mathrm{PaO}_{2} / \mathrm{FiO}_{2}$ and central venous-to-arterial carbon dioxide gap $\left(\mathrm{dCO}_{2}\right)$ will be calculated every $6 \mathrm{~h}$ until $72 \mathrm{~h}$ after surgery. On the first postoperative day (POD), a chest X-ray will be performed and repeated on the following days if the development of pulmonary complications are suspected. The chest X-ray will be evaluated by an independent, trained radiologist who will not be involved in the study. Continuous epidural analgesia and intermittent intravenously administered analgesia (paracetamol or metamizol) will be introduced, and evaluated effective if a Numeric Pain Rating Scale (NPRS) score is lower than 3 points.

During postoperative care, continuous intraabdominal pressure (IAP) monitoring via a direct intraperitoneal catheter, placed before closure of the abdominal wall, will be performed to eliminate bias caused by the elevation of IAP.

Patients' clinical progress and secondary endpoints will be monitored by daily SOFA scores, laboratory and physical examinations.

Postoperative hydration and vasopressor therapy will be directed by $\mathrm{MAP}, \mathrm{ScvO}_{2}, \mathrm{dCO}_{2}$ and arterial lactate levels. PRBC units will be transfused if decreased hemoglobin $(\mathrm{Hb})$ levels result in tissue oxygenation disorders or become symptomatic (hypotension, dizziness or weakness develop). Fresh frozen plasma will be given if the prothrombin International Normalized Ratio (INR) > 1.5. Platelet suspension units will be given according to the Transfusion Guidelines of the Hungarian National Blood Transfusion Service.

In both groups, patients will be allowed to drink clear fluids immediately after surgery and the use of chewing gum will be encouraged. Prokinetics and an oral liquid diet using a drinking formula will be started on POD 1 and patients will begin active mobilization. The nasogastric tube will be removed on the morning of POD 1 .

\section{From postoperative day 4 (POD 4 to $P O D$ 28, follow-up)}

During the follow-up period, secondary endpoints, inhospital stay, 28-day and in-hospital mortality will also be evaluated.

Figure 2 shows the CONSORT flowchart of the trial.

\section{Study arms and assigned intraoperative interventions}

A total number of 40 patients with bladder cancer submitted to general anesthesia and open radical cystectomy and urinary diversion will be enrolled in this study. An equal number of patients will be randomized into the two groups.

Patients randomized into the SG group undergo an alveolar recruitment maneuver using the sustained airway pressure by the CPAP method, applying $30 \mathrm{cmH}_{2} \mathrm{O}$ PEEP for $30 \mathrm{~s}$ followed by a decremental PEEP titration procedure directed by Cstat. During the PEEP titration procedure, PEEP will be decreased from $14 \mathrm{cmH}_{2} \mathrm{O}$ by 2 $\mathrm{cmH}_{2} \mathrm{O}$ every 4 min, until a final PEEP of $6 \mathrm{cmH}_{2} \mathrm{O}$ is reached. On each level of PEEP, ABGs will be collected and evaluated. Optimal PEEP is considered as the PEEP value resulting the highest possible Cstat measured by the ventilator. After the PEEP titration procedure, lungprotective mechanical ventilation will be performed using optimal PEEP and low tidal volumes and ARM will be performed every $60 \mathrm{~min}$.

Patients randomized into the CG group will undergo an alveolar recruitment maneuver using the sustained airway pressure by the CPAP method, applying 30 $\mathrm{cmH}_{2} \mathrm{O}$ PEEP for $30 \mathrm{~s}$ followed by low-tidal-volume LPV using a PEEP value of $6 \mathrm{cmH}_{2} \mathrm{O}$ and ARM will be repeated every $60 \mathrm{~min}$. 


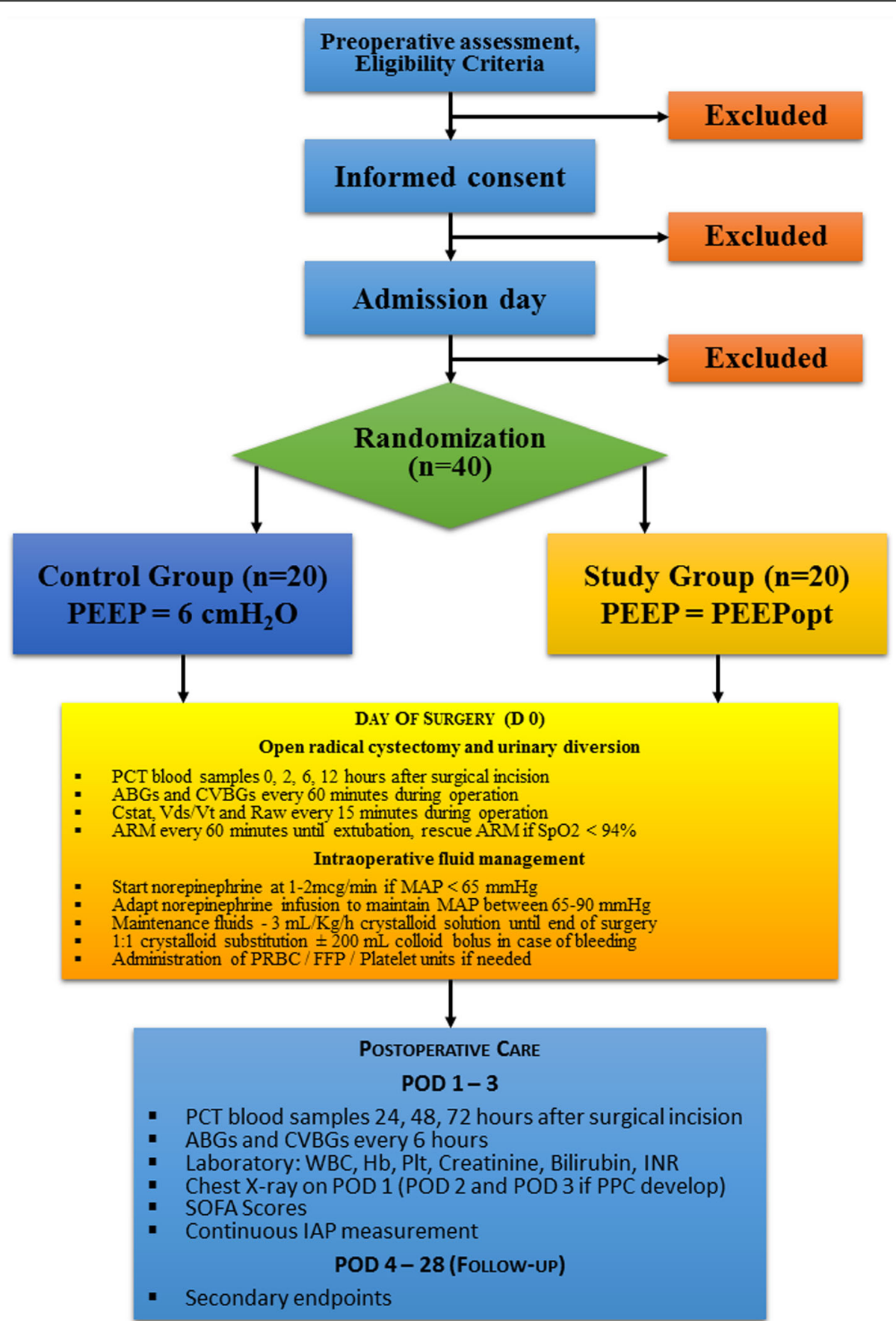

Fig. 2 Consolidated Standards of Reporting Trials (CONSORT) flowchart. PEEP positive end-expiratory pressure, PCT procalcitonin, ABGs arterial blood gas sample, CVBGs central venous blood gas sample, Cstat static pulmonary compliance, Vds Nt dead space fraction, Raw airway resistance, MAP mean arterial pressure, ARM alveolar recruitment maneuver, PRBC packed red blood cell, FFP fresh frozen plasma, IAP intraabdominal pressure

\section{Data monitoring}

Data monitoring will be performed centrally for quality control purposes by an external, independent physician, who will not be involved in the study. Monitoring will evaluate the progress of the study and verify the accuracy and completeness of the data recording (CRF, source data, Informed Consent Forms and outcome variables).

\section{Statistics}

Data will be analyzed by the research team in collaboration with a medically versed biostatistician after completion of the trial. There will be no interim analysis. Statistical analysis will be conducted on an intention-totreat basis. IBM SPSS 20.0 statistical software will be used for analysis. 
It is expected that the majority of source data will be recorded onto CRF; nonetheless, before starting the data analysis, the mechanism and pattern of missing data will be evaluated and these findings will be used to determine whether they have had an impact on the statistical analysis and results and how they can be managed.

Data distribution will be tested by the KolmogorovSmirnov analysis. Normally distributed data will be presented as mean and standard deviation (SD) and skewed data as median (interquartile range). Comparing related samples, the paired and unpaired $t$ test will be used for normally distributed data and the Wilcoxon signed rank test and Mann-Whitney $U$ test for skewed data. Differences in proportions will be evaluated using the Fisher's exact test, and risk ratio with associated 95\% confidence interval (CI). Analysis of the primary endpoint (PPC) will be carried out by the unpaired Student's $t$ test (95\% CI). A two-way, repeated-measures analysis of variance (two-way RM ANOVA) will be used to compare the groups' serum PCT levels. The relationship between PCT levels and organ dysfunctions will be evaluated using the Pearson correlation. Statistical analysis of SOFA scores, ICU days, in-hospital stay, in-hospital and 28-day mortality data of groups will be implemented by the chisquare test. A $P$ value $<0.05$ will be considered significant.

\section{Adverse events and interruption of the trial}

Every patient included in the trial will receive daily visits from an intensive care therapist and urologist in charge from POD 1 until leaving the hospital. During ICU stay, and if necessary on the intermediate care unit, all patients will be continuously monitored. The study nurse will be responsible for collecting blood samples and will record relevant required data onto CRF. During the outof-hospital follow-up period (until POD 28) patients' progress, particularly deterioration will be checked by daily phone-call visits.

The investigators will monitor the patients for any adverse events (AEs), which are defined as severe or prolonged hypotension (systolic blood pressure $<90 \mathrm{mmHg}$ ) and significant cardiac arrhythmias associated with the PEEP titration procedure. AEs will be documented on the CRF and the principal investigator will be informed.

Serious adverse events (SAEs) are defined as severe barotrauma leading to pneumothorax, significant prolongation of hospitalization, persistent or significant disability or incapacity, and severe deterioration (life-threatening state or even death) associated with the PEEP titration procedure. All treatment-related SAEs will be recorded and reported to the Hungarian Scientific and Medical Research Council Ethics Committee and the Local Ethics Committees. If any SAEs occur, the trial will be interrupted and an investigation will be performed.

\section{Duration of the trial}

The annual number of open radical cystectomy and urinary diversion is around 100 in the two study centers. Recruitment of the participants is expected within 18 months. The final data collection and estimated completion date of the trial is March 2018.

\section{Discussion}

This investigator-initiated, pragmatic, interventional, prospective, randomized controlled trial will assess the possible benefits and disadvantages of an individualized lung-protective mechanical ventilation strategy during open radical cystectomy and urinary diversion as indicated mainly by PPC and the inflammatory response.

PPC can develop after major abdominal surgery. Impaired gas exchange may lead to secondary disorders (delayed return of gastrointestinal function, renal dysfunction, cardiac disorders, etc.) resulting in prolonged hospitalization time and increased cost of hospital care [15-17]. The impact of an inappropriate intraoperative mechanical ventilation-caused inflammatory response both systemic and intrapulmonary -, on these complications is still uncertain.

Surgery induces an inflammatory response that is necessary for postoperative recovery [18-21]. Inappropriate mechanical ventilation can also cause an inflammatory response, which can lead to AEs such as pulmonary complications and distant organ dysfunction. Applying an individualized lung-protective ventilatory strategy during general anesthesia may reduce the degree of inflammation and decrease the incidence of pulmonary and extrapulmonary complications in the postoperative period, thereby contributing to shorter hospitalization time and reduced cost of hospital care [3-5].

Radical cystectomy and urinary diversion is considered major surgery with an operating time lasting for several hours. This gives the potential for inappropriate intraoperative ventilatory management causing further harm by exacerbating the surgery-induced inflammatory response, hence causing more postoperative complications. Titrating PEEP and performing regular ARMs during the anesthesia of these patients certainly has a strong pathophysiological rationale with potential benefits as indicated by recent clinical trials [4-7, 14], but this strategy is also cumbersome, time consuming and, due to the numerous blood gas samplings required, may be costly. Therefore, testing our hypothesis in a clinical study is necessary to answer these questions.

The potential implications of our results can further improve our knowledge on the effects of optimal intraoperative ventilatory strategies and, in the case of positive results, these may not only be applicable to patients with bladder cancer undergoing radical cystectomy and 
urinary diversion, but presumably to all patients undergoing similar types of major abdominal surgery.

\section{Trial status}

The trial is ongoing.

\section{Additional file}

Additional file 1: SPIRIT 2013 Checklist: recommended items to address in a clinical trial protocol and related documents. (DOCX $52 \mathrm{~kb}$ )

\begin{abstract}
Abbreviations
ABGs: Arterial blood gas samples; ARDS: Acute respiratory distress syndrome; ARM: Alveolar recruitment maneuver; ASA: American Society of Anesthesiologists; BE: Base excess; BMI: Body Mass Index; CG: Control group; Cl: Confidence interval; COPD: Chronic obstructive pulmonary disease; CPAP: Continuous positive airway pressure; CRF: Case Report Form; Cstat: Static pulmonary compliance; CT: Computer tomography; CVBGs: Central venous blood gas samples; $\mathrm{dCO}_{2}$ : Central venous-to-arterial carbon dioxide gap; ECG: Electrocardiogram; $\mathrm{EtCO}_{2}$ : End-tidal carbon dioxide tension; $\mathrm{FiO}_{2}$ : Fraction of inspired oxygen; GOLD: Global Initiative for Chronic Obstructive Lung Disease; HR: Heart rate; IAP: Intraabdominal pressure; IBW: Ideal bodyweight; ICU: Intensive care unit; INR: International Normalized Ratio; LMWH: Low-molecular-weight heparin; LPV: Lung-protective ventilation; MAP: Mean arterial pressure; NPRS: Numeric Pain Rating Scale; NRS 2002: Nutritional risk screening; NYHA: New York Heart Association; $\mathrm{PaO}_{2}$ : Partial pressure of arterial oxygen; PCT: Procalcitonin; PEEP: Positive end-expiratory pressure; POD: Postoperative day; PPC: Postoperative pulmonary complications; PRBC: Packed red blood cells; Raw: Airway resistance; RFRI: Respiratory Failure Risk Index; $\mathrm{ScVO}_{2}$ : Central venous oxygen saturation; SD: Standard deviation; SG: Study group; SOFA: Sequential Organ Failure Assessment; SPIRIT: Standard Protocol Items: Recommendation for Interventional Trials; $\mathrm{SpO}_{2}$ : Oxygen saturation; $\mathrm{StHCO}^{3-}$ : Standard bicarbonate; TV: Tidal volume; Vds/Nt: Dead space fraction; VILI: Ventilator-induced lung injury
\end{abstract}

\section{Acknowledgements}

We thank all the contributors and collaborators of our trial for their support.

\section{Funding}

This study is supported by internal departmental funding from Péterfy

Sándor Hospital and the University of Szeged.

\section{Availability of data and materials}

Not applicable.

\section{Authors' contributions}

ZR and ZM wrote the manuscript together with IL, EK and PTB. The study protocol was designed by ZR and ZM in close collaboration with IB and ZB. IL was involved in designing the statistical methods of the study. FG, ES, GPB, ER and EH will collaborate in patient recruitment and collection of data. $Z M$ is the study director and ZR is the principal investigator of the trial. All authors read and approved the final manuscript.

\section{Authors' information}

Not applicable.

\section{Ethics approval and consent to participate}

The study was approved by the Hungarian Scientific and Medical Research Council Ethics Committee (Egészségügyi Tudományos Tanács Tudományos Kutatás Etikai Bizottság ETT-TUKEB; chairperson: Professor Dr. Zsuzsanna Schaff; registration number 21586-4/2016/EKU) on 17 June 2016 and the Local Ethics Committee of Péterfy Sándor Hospital Budapest (Péterfy Sándor utcai Kórház Intézeti Kutatásetikai Bizottság IKEB; chairperson: Dr. Mária Vas; registration number CO-338-045) on 12 September 2016 and the Regional Ethics Committee of the University of Szeged (Regionális Humán Orvosbiológiai Tudományos és Kutatásetikai Bizottság RKEB; chairperson: Dr. Tibor Wittmann; registration number 149/2016-SZTE) on 19 September 2016. This study is conducted in accordance with the Declaration of Helsinki and was prospectively registered on 5 October 2016 at https://clinicaltrials.gov with the trial identification number NCT02931409. Participants fulfilling the inclusion criteria will sign an Informed Consent Form during their perioperative assessment. Withdrawal of consent may be initiated by the participant at any time during the trial.

\section{Consent for publication}

Not applicable.

\section{Competing interests}

The authors declare that they have no competing interests.

\section{Publisher's Note}

Springer Nature remains neutral with regard to jurisdictional claims in published maps and institutional affiliations.

\section{Author details}

'Department of Anaesthesiology and Intensive Care, Péterfy Sándor Hospital, Péterfy Sándor u. 8-20, Budapest 1076, Hungary. ${ }^{2}$ Department of

Anaesthesiology and Intensive Therapy, University of Szeged, Semmelweis u. 6, Szeged 6725, Hungary. ${ }^{3}$ Department of Urology, Péterfy Sándor Hospital, Péterfy Sándor u. 8-20, Budapest 1076, Hungary. ${ }^{4}$ Department of Urology, University of Szeged, Kálvária sgt.57, Szeged 6725, Hungary.

Received: 19 January 2017 Accepted: 21 July 2017

Published online: 11 August 2017

\section{References}

1. Slutsky AS, Ranieri VM. Ventilator-induced lung injury. N Engl J Med. 2013; 369:2126-36.

2. Ricard J-D, Dreyfuss D, Saumon G. Ventilator-induced lung injury. Eur Respir J. 2003;22 Suppl 42:2-9.

3. Futier $\mathrm{E}$, Constantin J-M, Paugam-Burtz $\mathrm{C}$, et al. A trial of intraoperative low-tidal-volume ventilation in abdominal surgery. N Engl J Med. 2013; 369:428-37

4. Hemmes SN, Gama De Abreu M, Pelosi P, et al. High versus low positive end-expiratory pressure during general anaesthesia for open abdominal surgery (PROVHILO trial): a multicentre randomised controlled trial. Lancet. 2014;384:495-503

5. Sutherasan $Y$, Vargas $M$, Pelosi P. Protective mechanical ventilation in the non-injured lung: review and meta-analysis. Crit Care. 2014;18:211.

6. Futier $\mathrm{E}$, Constantin $\mathrm{J}-\mathrm{M}$, Pelosi $\mathrm{P}$, et al. Intraoperative recruitment maneuver reverses detrimental pneumoperitoneum-induced respiratory effects in healthy weight and obese patients undergoing laparoscopy. Anesthesiology. 2010;113:1310-9.

7. Whalen FX, Gajic O, Thompson GB, et al. The effects of the alveolar recruitment maneuver and positive end-expiratory pressure on arterial oxygenation during laparoscopic bariatric surgery. Anesth Analg. 2006; 102:298-305.

8. Mols G, Priebe H-J, Guttmann J. Alveolar recruitment in acute lung injury. $\mathrm{Br}$ J Anaesth. 2006;96:156-66.

9. Talley HC, Bentz N, Georgievski J, et al. Anesthesia providers' knowledge and use of alveolar recruitment maneuvers. J Anesth Clin Res. 2012;3:325.

10. Chacko J, Rani U. Alveolar recruitment maneuvers in acute lung injury/acute respiratory distress syndrome. Indian J Crit Care Med. 2009;13:1-6.

11. Siobal MS, Ong H, Valdes J, et al. Calculation of physiologic dead space: comparison of ventilator volumetric capnography to measurements by metabolic analyzer and volumetric $\mathrm{CO}_{2}$ monitor. Respir Care. 2013:58: $1143-51$.

12. El-Baradey GF, El-Shamaa NS. Compliance versus dead space for optimum positive end expiratory pressure determination in acute respiratory distress syndrome. Indian J Crit Care Med. 2014;18:508-12.

13. Pelosi P, Gama De Abreu M, Rocco PRM. New and conventional strategies for lung recruitment in acute respiratory distress syndrome. Crit Care. 2010; 14:210.

14. Vargas $M$, Sutherasan $Y$, Gregoretti C, et al. PEEP role in ICU and operating room: from pathophysiology to clinical practice. Sci World J. 2014. doi:10. 1155/2014/852356

15. Desborough JP. The stress response to trauma and surgery. $\mathrm{Br} J$ Anaesth. 2000;85:109-17. 
16. Lindberg $\mathrm{M}$, Hole $\mathrm{A}$, Johnsen $\mathrm{H}$, et al. Reference intervals for procalcitonin and C-reactive protein after major abdominal surgery. Scand J Clin Lab Invest. 2002;62:189-94.

17. Sido $B$, Teklote $J R$, Hartel $M$, et al. Inflammatory response after abdominal surgery. Best Pract Res Clin Anaesthesiol. 2004;18:439-54.

18. Sarbinowski R, Arvidsson S, Tylman M, et al. Plasma concentration of procalcitonin and systemic inflammatory response syndrome after colorectal surgery. Acta Anaesthesiol Scand. 2005;49:191-6.

19. Mokart D, Merlin M, Sannini A, et al. Procalcitonin, interleukin 6 and Systemic Inflammatory Response Syndrome (SIRS): early markers of postoperative sepsis after major surgery. Br J Anaesth. 2005;94:767-73.

20. Bogár L, Molnár Z, Tarsoly P, et al. Serum procalcitonin level and leukocyte antisedimentation rate as early predictors of respiratory dysfunction after oesophageal tumour resection. Crit Care. 2006;10:R110.

21. Minami E, Ito S, Sugiura T, et al. Markedly elevated procalcitonin in early postoperative period in pediatric open heart surgery: a prospective cohort study. J Intensive Care. 2014;2:38.

22. Trasy D, Tánczos K, Németh $M$, et al. Early procalcitonin kinetics and appropriateness of empirical antimicrobial therapy in critically ill patients. A prospective observational study. J Crit Care. 2016;34:50-5.

Submit your next manuscript to BioMed Central and we will help you at every step:

- We accept pre-submission inquiries

- Our selector tool helps you to find the most relevant journal

- We provide round the clock customer support

- Convenient online submission

- Thorough peer review

- Inclusion in PubMed and all major indexing services

- Maximum visibility for your research

Submit your manuscript at www.biomedcentral.com/submit
Biomed Central 